\title{
Microstructural Changes and Impact Toughness of Fill Pass in X80 Steel Weld Metal
}

\author{
Fang Bai ${ }^{1,2}$, Hongsheng Ding ${ }^{1}$, Lige Tong ${ }^{3, *}$, , Liqing Pan ${ }^{4, *}$ and Li Wang ${ }^{3}$ \\ 1 School of Mathematics and Physics, University of Science and Technology Beijing, Beijing 100083, China \\ 2 Pipeline Institute, China Petroleum Pipeline Engineering CO., LTD., Langfang 065000, China \\ 3 School of Energy and Environmental Engineering, University of Science and Technology Beijing, \\ Beijing 100083, China \\ 4 College of Science, China Three Gorges University, Yichang 443002, China \\ * $\quad$ Correspondence: tonglige@me.ustb.edu.cn (L.T.); lpan@ctgu.edu.cn (L.P.); Tel.: +86-10-6233-2741 (L.T. \& L.P.)
}

Received: 27 July 2019; Accepted: 14 August 2019; Published: 16 August 2019

\begin{abstract}
Multi-pass welding is used in high-pressure and thick-walled pipes in natural gas and oil pipelines. When a welding layer of a welded joint is subjected to different welding thermal cycles, its microstructure and properties change, thereby affecting the overall welding performance. In this study, the temperature and microstructural variations of the fill pass 2 (FP2) in the entire welding process were investigated by combining the thermal cycle with the cascade welding method. The original FP2 and FP2 after double thermal cycles had the worse deformation ability by tensile test. The toughness of FP2 improved after a single thermal cycle, decreased after double thermal cycles, and improved again after triple thermal cycles. The content of martensite-austenite (M-A) constituents and the average grain size of FP2 in the cascade samples were inversely proportional to FP2 toughness. Massive M-A constituents and their unique distribution at the inter-critical temperature were harmful to weld metal toughness. Controlling the size and fraction of M-A constituents can improve weld metal toughness.
\end{abstract}

Keywords: weld metal; thermal cycle; M-A constituent; impact toughness; grain size

\section{Introduction}

Multi-pass welding is used in high-pressure and thick-walled pipes in natural gas and oil pipelines and other industries [1,2]. The X80 pipeline steel is used extensively in pipeline construction as a base metal in multi-pass welded joints. The microstructure of multi-pass welded joints generally comprises the original columnar weld metal and the weld metal that has been reheated at different temperatures and different durations during the subsequent welding layer [3-5]. The destruction of the previous columnar morphology in the reheating process results in a heterogeneous microstructure. In addition to welding parameters, the reheated zone is a determining factor that controls the low-temperature toughness of the entire welded joint $[6,7]$.

Although martensite-austenite (M-A) constituents are not the main components of weld metal, their effects on welding properties are complex. Dispersed and tiny M-A constituents do not affect weld metal toughness [8,9]. Massive M-A constituents have a greater effect on toughness than slender M-A constituents [10-12]. Toughness improves with the increase in slender M-A constituents but decreases with the increase in massive ones $[13,14]$. However, research has also shown the improvement in toughness is due to the formation of massive M-A constituents [15]. In addition to the morphology, the size of M-A constituents will also affect weld metal toughness [16-18]. Li et al. [19] reported that the inter-critically reheated heat-affected zone (HAZ) toughness of X70 pipeline steel does not completely deteriorate because the $\mathrm{M}-\mathrm{A}$ constituents of the steel are small and their content is low. Hence, $\mathrm{M}-\mathrm{A}$ 
constituents should be controlled to improve toughness. Kumar et al. [20] studied the effect of welding thermal cycles on the microstructures and mechanical properties of HAZ of HY85 steel. Their thermal simulation results suggested that massive and slender $\mathrm{M}-\mathrm{A}$ constituents that form at the prior-austenite grain boundaries (PAGBs) and lath grains can reduce toughness. Wang et al. [21] studied the effect of welding pass on the microstructure and toughness of the reheated zone of multi-pass weld metal. The reheated zone was also studied using other simulation methods. Reduced toughness in this zone is due to the necklace-type M-A constituents. Subsequently, the toughness improves during welding. All the aforementioned studies were conducted through thermal simulation experiments. However, the actual and simulated weld microstructures were different. The change of a weld layer during the welding process can reveal the effect of the welding thermal cycle on the weld microstructure.

In this study, cascade welding was used to obtain the weld metal after each welding thermal cycle. Some studies have shown that M-A constituents are the main factor affecting weld metal toughness [22]. However, other factors, such as the fraction of each phase and the grain size in the microstructure, also affect weld metal toughness. Welding thermal cycles affect the relationship between each factor and the impact toughness of weld metal. This study likewise observed the change in the weld metal microstructure, particularly the M-A constituents and the grain size after each welding thermal cycle. The change in toughness of each weld layer under welding thermal cycles was combined with the residual stress in the welded joint to determine the weld layers with high risk.

\section{Materials and Methods}

\subsection{Materials and Welding Parameters}

An $18.4 \mathrm{~mm}$ thick ferrite/bainite dual-phase X80 pipeline steel was used in the experiment. The mechanical properties of X80 pipeline steel are shown in Table 1 . The welding materials were a $\varphi 3.2 \mathrm{~mm}$ LB-52 welding rod and a $\varphi 2.0 \mathrm{~mm}$ self-shielded flux-cored JC-30 wire. Table 2 lists the welding parameters, Table 3 shows the chemical composition of X80 pipeline steel, and Tables 4 and 5 show the chemical composition of deposited metal and weld metal. The final chemical composition of the weld metal was the complex fusion of the base metal and the deposited metal. The chemical compositions of base metal, deposited metal, and weld metal were measured by spectrometer (ARTUS 8).

Table 1. Mechanical properties of X80 pipeline steel.

\begin{tabular}{ccccc}
\hline Material & Yield Strength $\boldsymbol{R}_{\mathrm{t} 0.5} \mathbf{( M P a )}$ & Tensile Strength $\boldsymbol{R}_{\mathrm{m}} \mathbf{( M P a )}$ & YS $\left(\boldsymbol{R}_{\mathrm{t} 0.5}\right) / \mathrm{TS}\left(\boldsymbol{R}_{\mathrm{m}}\right)$ & Elongation $(\%)$ \\
\hline X80 & 605 & 700 & 0.86 & 20.5 \\
\hline
\end{tabular}

Table 2. Welding parameters for X80 pipeline steel.

\begin{tabular}{cccccc}
\hline Parameters & $\begin{array}{c}\text { Interpass } \\
\text { Temperature }\left({ }^{\circ} \mathbf{C}\right)\end{array}$ & $\begin{array}{c}\text { Arc Voltage } \\
(\mathbf{V})\end{array}$ & $\begin{array}{c}\text { Welding } \\
\text { Current }(\mathbf{A})\end{array}$ & $\begin{array}{c}\text { Welding Speed } \\
(\mathbf{c m} / \mathbf{m i n})\end{array}$ & $\begin{array}{c}\text { Weld Heat } \\
\text { Input }(\mathbf{k J} / \mathbf{c m})\end{array}$ \\
\hline Root weld & 100 & $19-20$ & $87-92$ & 5.38 & 20.5 \\
Fill pass 1 (FP1) & 100 & 20 & $200-210$ & 18.7 & 13.6 \\
Fill pass 2 (FP2) & 95 & 20 & $220-230$ & 16.1 & 17.1 \\
Fill pass 3 (FP3) & 103 & 19 & $210-230$ & 10.9 & 24.1 \\
Fill pass 4 (FP4) & 97 & 20 & $210-220$ & 9.34 & 28.2 \\
Fill pass 5 (FP5) & 101 & 20 & $210-220$ & 12.05 & 21.9 \\
Cap weld & 104 & 20 & $210-220$ & 7.9 & 33.4 \\
\hline
\end{tabular}

Table 3. Chemical composition of X80 pipeline steel.

\begin{tabular}{cccccccccccc}
\hline Content & $\mathbf{C}$ & $\mathbf{S i}$ & $\mathbf{M n}$ & $\mathbf{P}$ & $\mathbf{S}$ & $\mathbf{N b}$ & $\mathbf{C r}$ & $\mathbf{N i}$ & $\mathbf{M o}$ & $\mathbf{T i}$ & Al \\
\hline wt. $\%$ & 0.074 & 0.184 & 1.839 & 0.015 & 0.008 & 0.097 & 0.099 & 0.223 & 0.264 & 0.011 & 0.035 \\
\hline
\end{tabular}


Table 4. Chemical composition of deposited metal.

\begin{tabular}{cccccccccccc}
\hline Content & $\mathbf{C}$ & $\mathbf{S i}$ & $\mathbf{M n}$ & $\mathbf{P}$ & $\mathbf{S}$ & $\mathbf{N b}$ & $\mathbf{C r}$ & $\mathbf{N i}$ & $\mathbf{M o}$ & $\mathrm{Ti}$ & $\mathrm{Al}$ \\
\hline wt. $\%$ & 0.033 & 0.184 & 1.440 & 0.009 & 0.003 & 0.005 & 0.025 & 1.660 & 0.006 & 0.004 & 1.090 \\
\hline
\end{tabular}

Table 5. Chemical composition of weld metal.

\begin{tabular}{cccccccccccc}
\hline Content & $\mathbf{C}$ & $\mathbf{S i}$ & $\mathbf{M n}$ & $\mathbf{P}$ & $\mathbf{S}$ & $\mathbf{N b}$ & $\mathbf{C r}$ & $\mathbf{N i}$ & $\mathbf{M o}$ & $\mathbf{T i}$ & $\mathbf{A l}$ \\
\hline wt. $\%$ & 0.044 & 0.197 & 1.530 & 0.008 & 0.004 & 0.010 & 0.070 & 1.480 & 0.033 & 0.007 & 0.815 \\
\hline
\end{tabular}

\subsection{Experimental Method}

Multi-pass and cascade welding methods were combined. Fill passes (FPs) served as the main components of welded joints in multi-pass welding. The FP2 was studied because of its location; it underwent more thermal cycles than did the other FPs (i.e., FP3, FP4, FP5, and cap pass), and its changes represented those of the other FPs. Changes in the weld metal microstructure were observed after every thermal cycle. The cascade welding method was used from welding FP3.

The thermal cycles of FP2 were measured using a thermocouple. The length and width of the welding test plate of X80 pipeline steel was $300 \mathrm{~mm}$ and $150 \mathrm{~mm}$ separately. Two test plates were butted prior to the experiment and then root welding and FP1 were completed. A K-type thermocouple was used to measure the temperature, and an OMEGA OM-DAQ-USB-2401 (OMEGA, Houston, TX, USA) multichannel data acquisition module was used for data collection.

Most of the specimens in the paper were sampled by WED (wire electro-discharge). This method can produce specimens that easily meet the geometric-dimensional requirements, and which lack any significant changes in the mechanical properties [23].

Metallographic specimens (i.e., JT-2, JT-3, JT-4, JT-5, and JT-C) were taken from the cascade welding plate. The sampling direction was vertical to the direction of the cascade welding plate to ensure the surface of the weld metal was fully exposed. The test specimens are shown in Figure 1. The FP2 of sample JT-2 had the original welding microstructure, while the microstructures of the other specimens were obtained via single, double, triple, and quadruple thermal cycles. The FP2 is marked as black in Figure 1, and a Zeiss upright light microscope was utilized to study the microstructure of each specimen, which was etched with $4 \%$ nital. A microhardness tester (432SVD, Wilson, Norwood, MA, USA) was used to carry out a hardness test. A LePera etchant was applied to study the M-A constituents (shown as white). A scanning electron microscope (SEM; JSM 6360LV, Jeol, Japan) and a transmission electron microscope (JEM-2200FS, Jeol, Japan) were also used. For TEM specimens, first we took a $0.05 \mathrm{~mm}$ sheet vertical to the direction of the test plate. Then, we took out a $3 \mathrm{~mm}$ diameter circle from FP2, finally thinning it.

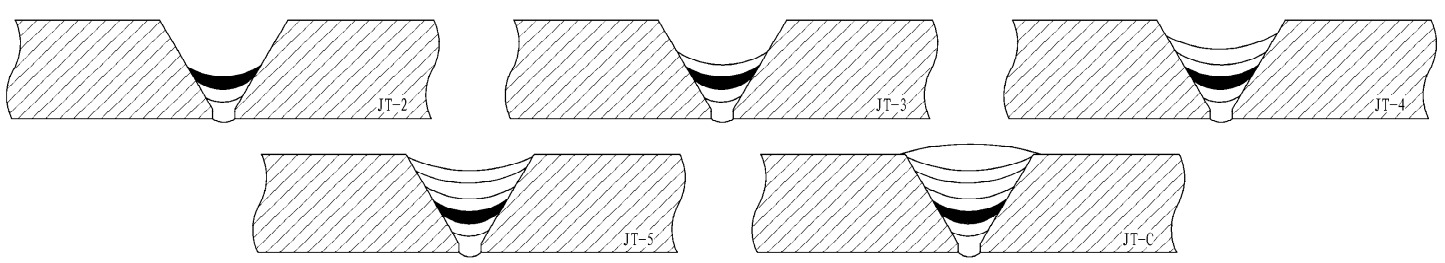

Figure 1. Specimens of cascade welding (FP2 is marked as black).

Tensile and impact test specimens were all sampled from the metallographic specimens of the cascade welding plate. The extraction scheme of the tensile specimen (including the dimensions of the specimen) is shown in Figure 2. Each group had three identical specimens and FP2 was located in the center working area. The extraction of the impact specimen and the dimensions are shown in Figure 3. The size of the specimens was $3.3 \mathrm{~mm} \times 10 \mathrm{~mm} \times 55 \mathrm{~mm}$ to ensure that the notch was only in FP2. The impact test temperature was $-20^{\circ} \mathrm{C}$. The fracture surfaces were also observed by 
SEM. The miniature tensile test (UTM4204, Suns, Shenzhen, China) and Charpy impact test machines (IMP450J Dynatup, Instron, Norwood, MA, USA) were used in the research. All the mechanical tests were carried out in accordance with the ASTM A370 standard. The total number of tensile samples was 15.

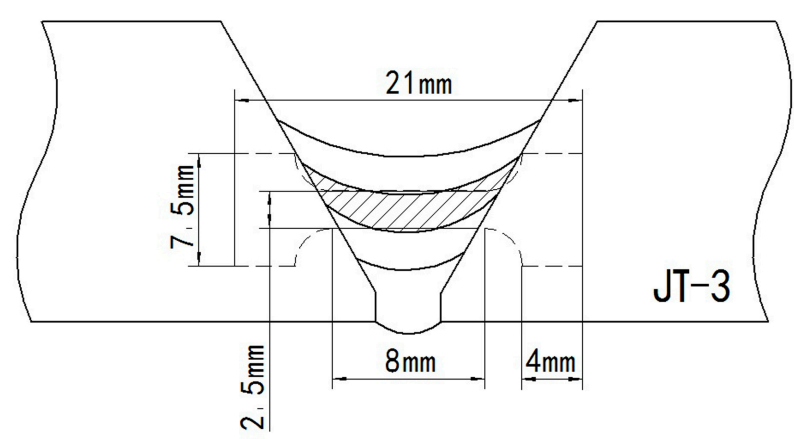

Figure 2. Location of the specimens in the tensile test.

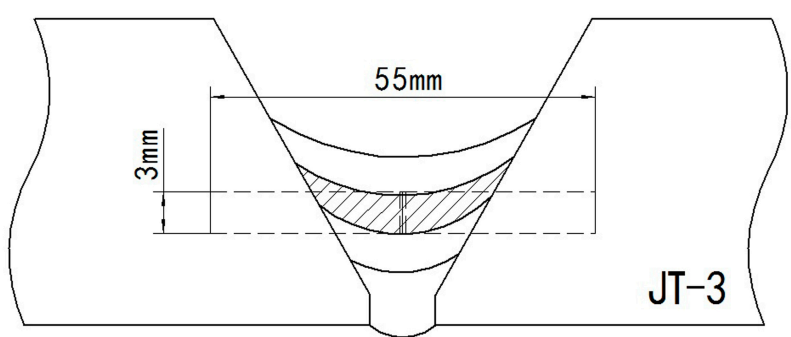

Figure 3. Location of the specimens in the impact test.

\section{Results and Discussion}

\subsection{Measurement of Welding Thermal Cycles}

The temperature change in FP2 of the welding plate was measured by a thermocouple. The welding thermal cycles experienced by FP2 in different cascade welding samples were different (Table 6). The thickness of FP2 was 2-3 mm, which resulted in different distances from the welding heat source. The FP2 microstructure in cascade sample JT-2 was the original weld metal, which was a columnar structure that did not undergo a thermal cycle. The FP2 of sample JT-3 was subjected to the single thermal cycle of FP3. Owing to the thickness of FP2, the heating peak temperature of the single thermal cycle $\mathrm{T}_{\mathrm{p} 1}$ measured by the thermocouple was at $1100-1300^{\circ} \mathrm{C}$, which was above the recrystallization temperature. The FP2 of sample JT-4 was subjected to double thermal cycles of FP3 and FP4. The second thermal cycle heating peak temperature $\mathrm{T}_{\mathrm{p} 2}$ measured by the thermocouple was at $750-1000{ }^{\circ} \mathrm{C}$. The thermal expansion curve of the welding material JC-30 used in the FPs was measured by a thermal simulation machine, and the inter-critical temperatures $\mathrm{A}_{\mathrm{c} 1}$ and $\mathrm{A}_{\mathrm{c} 3}$ were $700{ }^{\circ} \mathrm{C}$ and $880{ }^{\circ} \mathrm{C}$, respectively. Thus, the partial position of FP2 was subjected to the heating peak temperature at the inter-critical regions $\mathrm{A}_{\mathrm{c} 1}-\mathrm{A}_{\mathrm{c} 3}$. The FP2 of samples JT-5 and JT-C was subjected to triple and quadruple thermal cycles, respectively. As the number of weld FPs increased, the FP2 moved farther away from the welding heat source. Therefore, the difference in heating peak temperature between the third and fourth thermal cycles $\left(\mathrm{T}_{\mathrm{p} 3}\right.$ and $\mathrm{T}_{\mathrm{p} 4}$, respectively) was small. The $\mathrm{T}_{\mathrm{p} 3}$ and $\mathrm{T}_{\mathrm{p} 4}$, as measured by the thermocouple, were all less than $700^{\circ} \mathrm{C}$. 
Table 6. Thermal cycling conditions of each cascade sample.

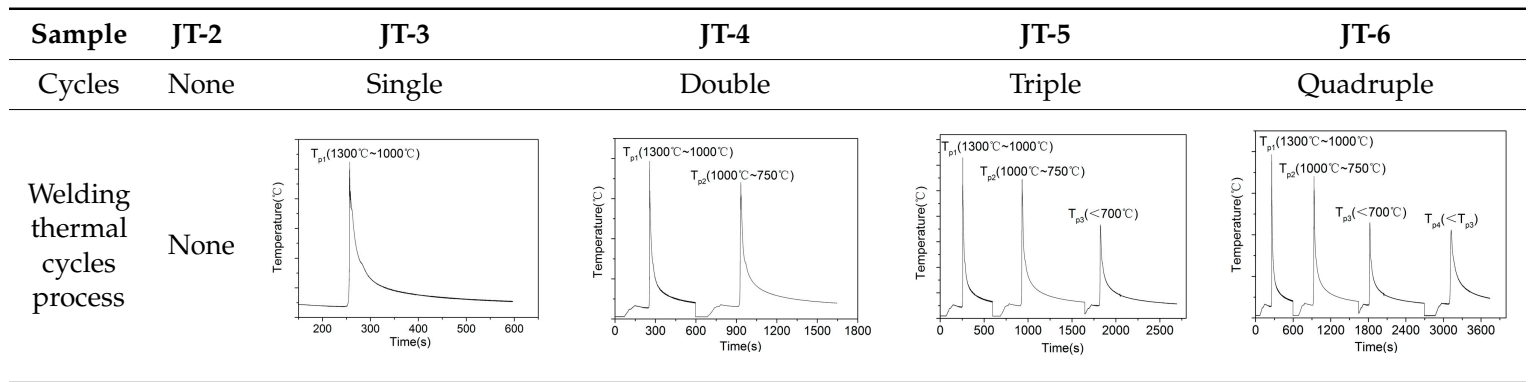

\subsection{Tensile Test and Hardness Test}

All the tensile tests were carried out at a nominal strain rate of $0.5 \mathrm{~mm} / \mathrm{min}$. The engineering stress-strain curves of each cascade specimen were measured (Figure 4a). The overall shape of the curves was basically the same. The specimens of JT- 5 and JT-C had a worse deformability than other specimens. The change in strength parameters such as tensile strength (TS), yield strength (YS), and the YS/TS ratio were also measured from the curves (Figure $4 \mathrm{~b}$ ). In pipeline steel, the yield-to-tensile strength ratio (i.e., YS/TS) reflects the strain hardening response of materials and can significantly influence the failure behavior of pipelines. The YS/TS ratio can also be measured to evaluate the properties of weld metal in pipeline engineering. Generally, a low YS/TS ratio is considered to provide high capacity for plastic deformation and enhance the margin of safety against failure [24]. In JT-2 and JT-4, FP2 had a higher YS/TS ratio which meant this weld metal had the worse ultimate deformation ability, while FP2 in JT-3 had the best deformation ability.
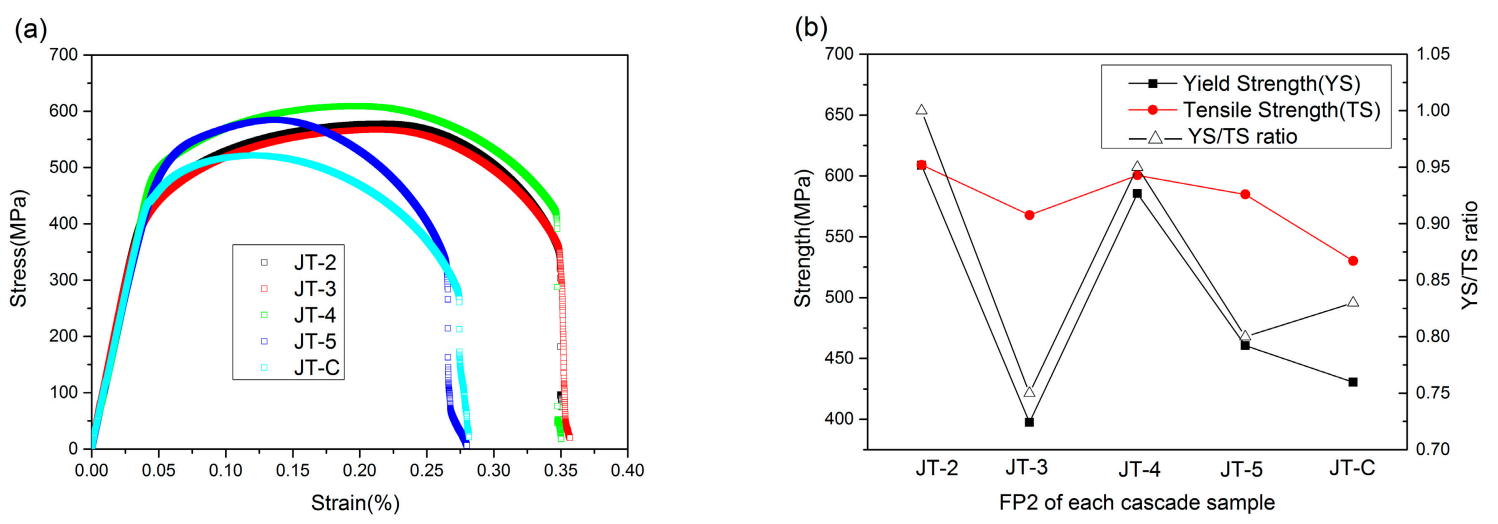

Figure 4. Tensile test of FP2 in each cascade sample: (a) stress-strain curves; (b) change in some strength parameters.

\subsection{Toughness Impact Test}

The results of the impact test showed that the FP2 in cascade sample JT-3 had excellent toughness, and the impact energy at $-20{ }^{\circ} \mathrm{C}$ of FP2 in cascade sample JT-3 could reach $\sim 50 \mathrm{~J}$, whereas that of FP2 in cascade sample JT-2 was only $\sim 20 \mathrm{~J}$ (Figure 5). Among the FP2 that underwent welding thermal cycles, the FP2 of sample JT-4 had the worst toughness with $\sim 33 \mathrm{~J}$. Therefore, weld metal toughness was improved by the single thermal cycle but decreased by the double thermal cycle. In the subsequent welding process, weld metal toughness was improved again when the third and fourth thermal cycles were performed. Therefore, the effect of welding thermal cycle on weld metal toughness depends on the number of thermal cycles. Wang et al. [21] also indicated that triple thermal cycles improve weld metal toughness. The test results of the current study implied that a large dispersion of the impact value still occurred even though the average impact energy of FP2 was improved by the thermal cycles. 


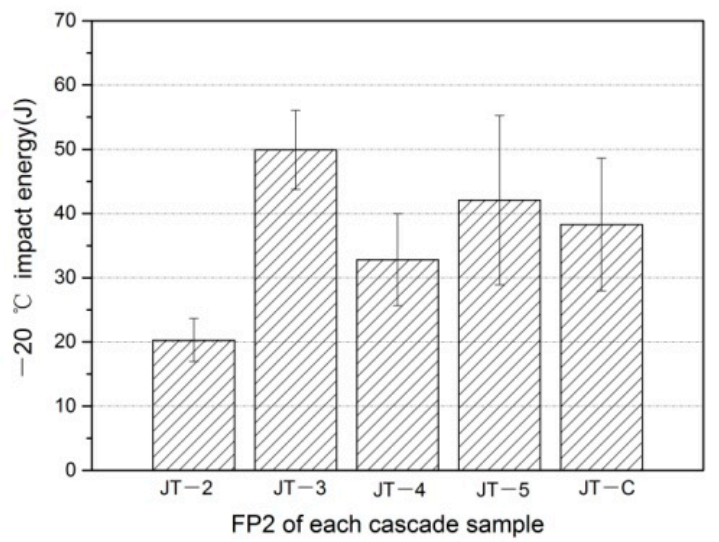

Figure 5. Impact toughness of each cascade sample.

\subsection{Hardness Test}

The hardness values of FP2 in each cascade were measured (Figure 6). A load of $10 \mathrm{~kg}$ was applied on the sample surface to obtain the hardness value. Moreover, FP2 in the sample JT-3 had the lowest hardness values with the best toughness. The FP2 in the sample JT-2 had the highest hardness values with the worst toughness. The law of hardness changes in FP2 in each cascade sample was in accordance with its relationship with toughness. Yield strength and tensile strength show a linear relationship with the Vickers hardness in some pipeline steel [25]. In the weld metal of pipeline steel, it had an approximate linear relationship between the strength and the Vickers hardness (Figure 6c).
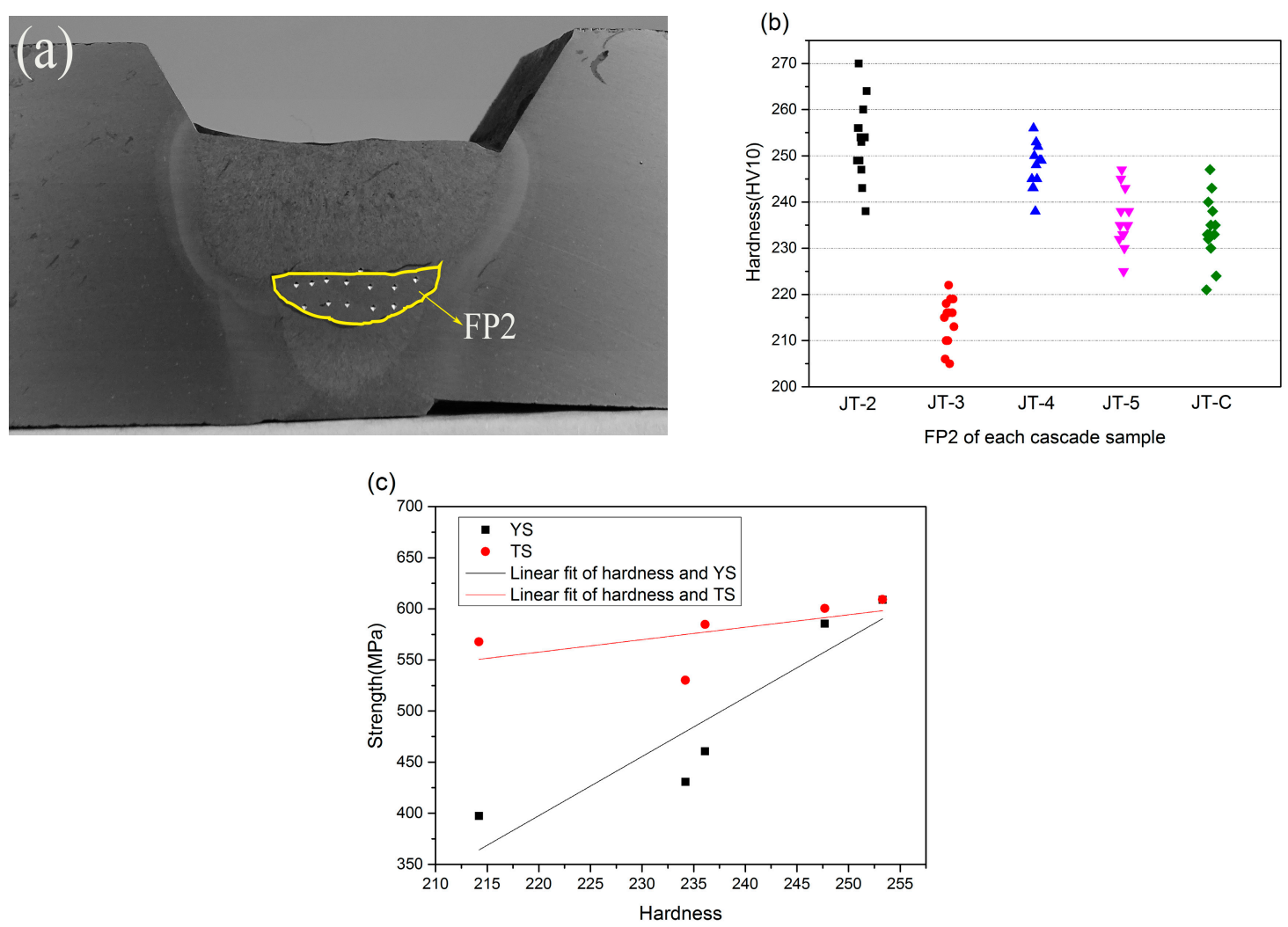

Figure 6. Hardness of FP2 in each cascade sample: (a) measured points; (b) hardness comparison; (c) relationship between the strength and the Vickers hardness. 


\subsection{Microstructure}

The FP2 of sample JT-2 was the original weld metal, and the microstructure was uniform. The microstructure of sample JT-2 was columnar with bainitic ferrite (BF) and granular bainite (GB), as shown in Figure 7 . The columnar structure was formed above $1500{ }^{\circ} \mathrm{C}$ in the weld metal.

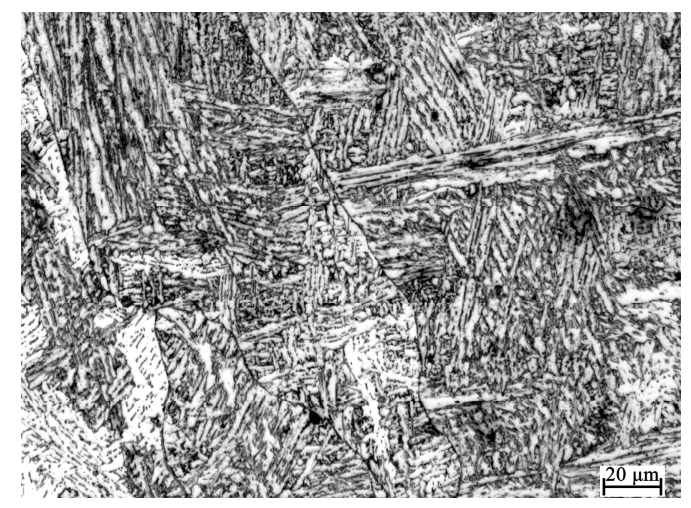

Figure 7. Microstructure of the FP2 of sample JT-2.

The FP2 had a certain thickness that resulted in different distances from the welding heat source. Hence, starting from sample JT-3, the FP2 microstructure began to be uneven, which caused microstructural inhomogeneity. The FP2 microstructure changed after the single thermal cycle of FP3 (Figure 8). The closest position to the heat source, where the austenite grains grew rapidly and coarse grains were obtained after cooling, was that of weld metal subjected to coarse grains (WM-CG, Figure 8a). The curve measurement process of the thermal cycle indicated that the maximum heating temperature of the single thermal cycle was approximately $1300{ }^{\circ} \mathrm{C}$. The position of FP2 that was slightly away from the heat source and where the grains in the structure were a mix of coarse and fine grains, was that of weld metal subjected to mixed coarse and fine grains (WM-CFG, Figure 8b). The maximum heating temperature of WM-CFG was above $1100{ }^{\circ} \mathrm{C}$. The position of FP2 that was farthest from the heat source and composed entirely of fine grains was that of weld metal subjected to fine grains (WM-FG, Figure 8c). The maximum heating temperature of WM-FG was in the range of 1000-1100 ${ }^{\circ} \mathrm{C}$. The PAGBs were clean in WM-CG, and BF and GB were mainly observed inside the grains. The average diameters of the coarse and fine grains were 50 and $15 \mu \mathrm{m}$, respectively.

The WM-CG, WM-CFG, and WM-FG regions in the FP2 of sample JT-3 disappeared after the welding effect of FP4. The majority of the matrix microstructure reverted to austenite owing to the high heating temperature near $\mathrm{A}_{\mathrm{c} 3}$. Moreover, PAGB was not clean (Figure 9a). Acicular ferrite (AF) and GB microstructure were mainly obtained, and M-A constituents were buried in these microstructures, making the constituents difficult to distinguish in the optical micrographs. The second maximum heating temperature in the double thermal cycles of this region was near $A_{c 3}$. When far from the heat source, M-A constituents were formed along the grain boundaries (GBs) but were not completely connected (Figure $9 \mathrm{~b}$ ). The yellow arrows point to the $\mathrm{M}-\mathrm{A}$ constituents. The second maximum heating temperature of this region was at the inter-critical regions $A_{c 1}-A_{c 3}$. The microstructure of the FP2 farthest from the heat source was similar to that in WM-CG, and the average grain size was $75 \mu \mathrm{m}$, which was larger than that in WM-CG. The main microstructures GB, BF, and AF in this region are shown in Figure 9c. The second maximum heating temperature of this region was also at the inter-critical temperatures $A_{c 1}-A_{c 3}$. The $\mathrm{M}-\mathrm{A}$ constituents were clearly distributed along the GBs, as shown by the TEM image in Figure $9 \mathrm{~d}$ (the black massive ones are M-A constituents). The M-A constituents formed in this region decorated the prior austenite grain boundaries like a necklace [26]. These necklace-type M-A constituents facilitated crack propagation and large cleavage fractures, which caused a dramatic loss in toughness [27]. Therefore, $\mathrm{M}-\mathrm{A}$ constituents were one reason for the low impact toughness of the FP2 of sample JT-4. 


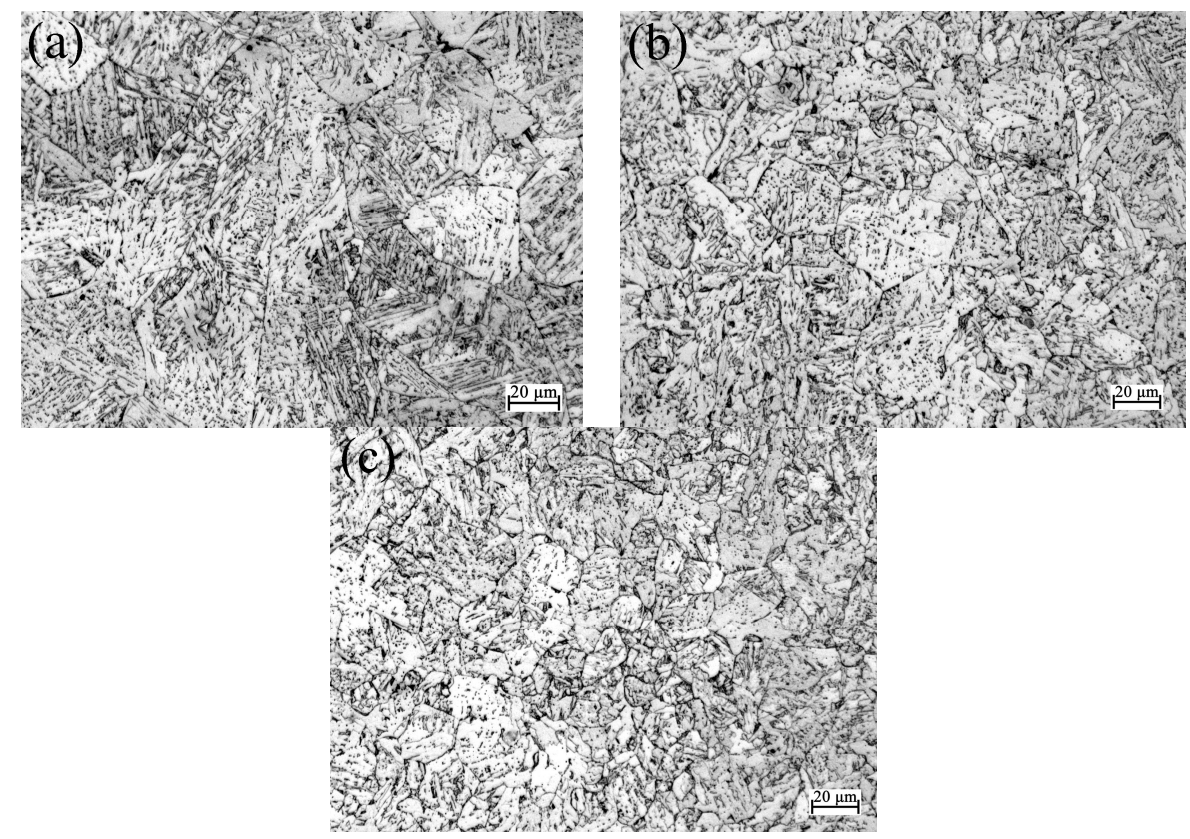

Figure 8. Microstructure of the FP2 of sample JT-3: (a) WM-CG; (b) WM-CFG; (c) WM-FG.
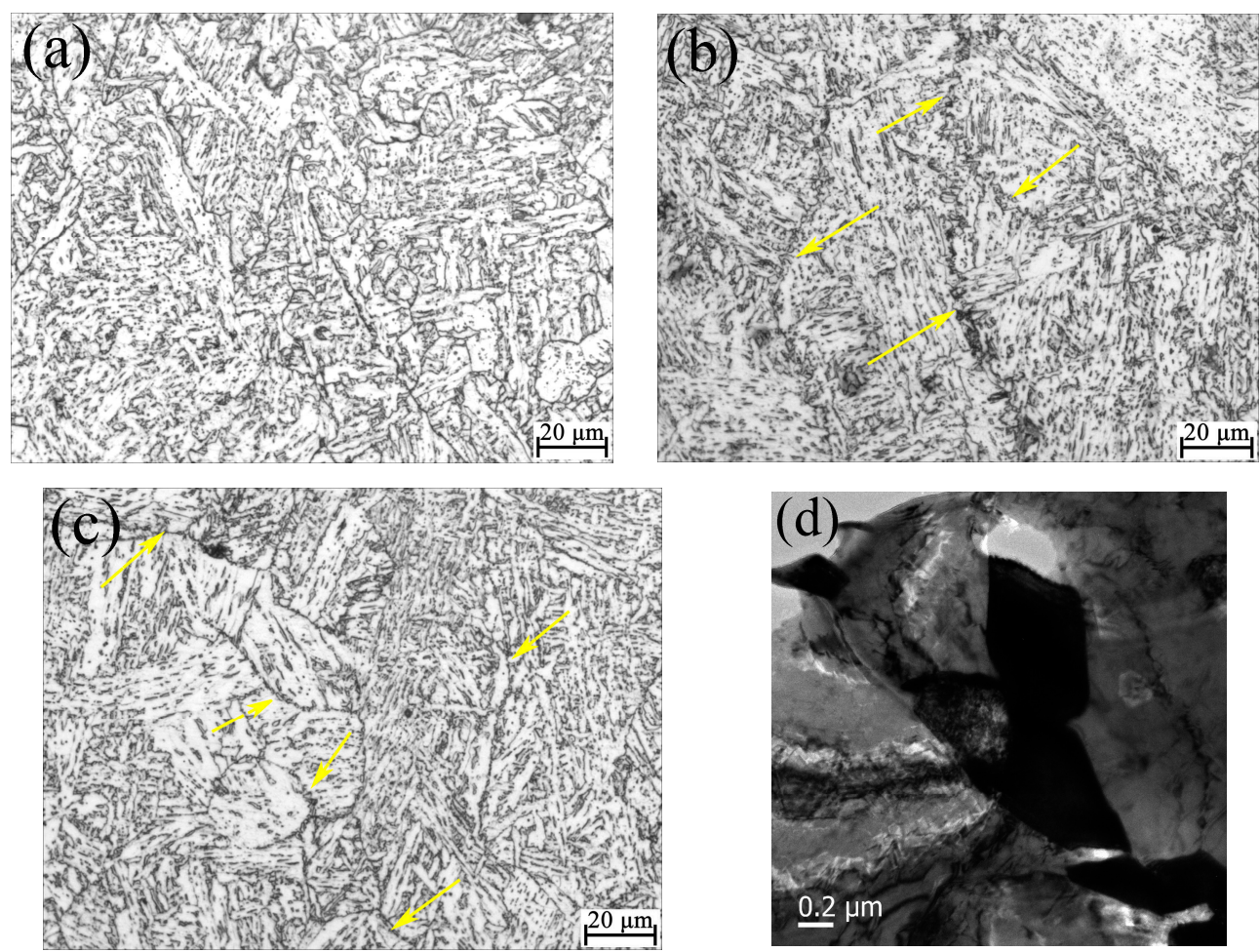

Figure 9. Microstructure of the FP2 of sample JT-4: (a) closest to the heat source; (b) slightly far from the heat source; (c) farthest from the heat source; (d) necklace-type M-A constituents.

The main microstructure of the FP2 of sample JT-5 after the welding effect of FP5 comprised GB, $\mathrm{BF}, \mathrm{AF}$, and some quasi-polygonal ferrite (QF) and polygonal ferrite (PF). Some M-A constituents were discontinuously distributed along the coarse GBs, whereas others were formed in GB and BF. Meanwhile, some M-A constituents were decomposed into small parts (the circle in Figure 10a). The TEM photographs of the FP2 of sample JT- 5 showed retained austenite, which was formed during tempering [28] (Figure 10b). Thus, the heating temperature was at the tempering range. 
The temperature measurement results indicated that FP2 was subjected to the third maximum heating peak temperature of approximately $700^{\circ} \mathrm{C}$ in the triple thermal cycles.
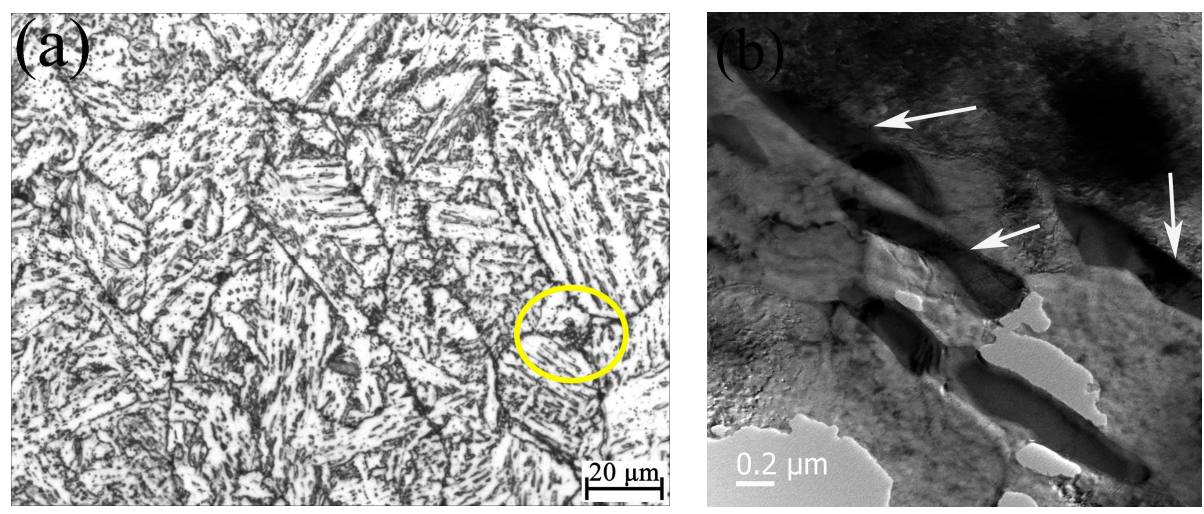

Figure 10. Microstructure of the FP2 of sample JT-5: (a) metallographic of sample JT-5; (b) TEM of retained austenite.

The FP2 microstructure after the cap pass was welded was found nearest to the heat source with QF and GB (Figure 11a). The main structure away from the heat source comprised QF and coarse GB (Figure 11b). The M-A constituents were distributed inside the GB and QF.
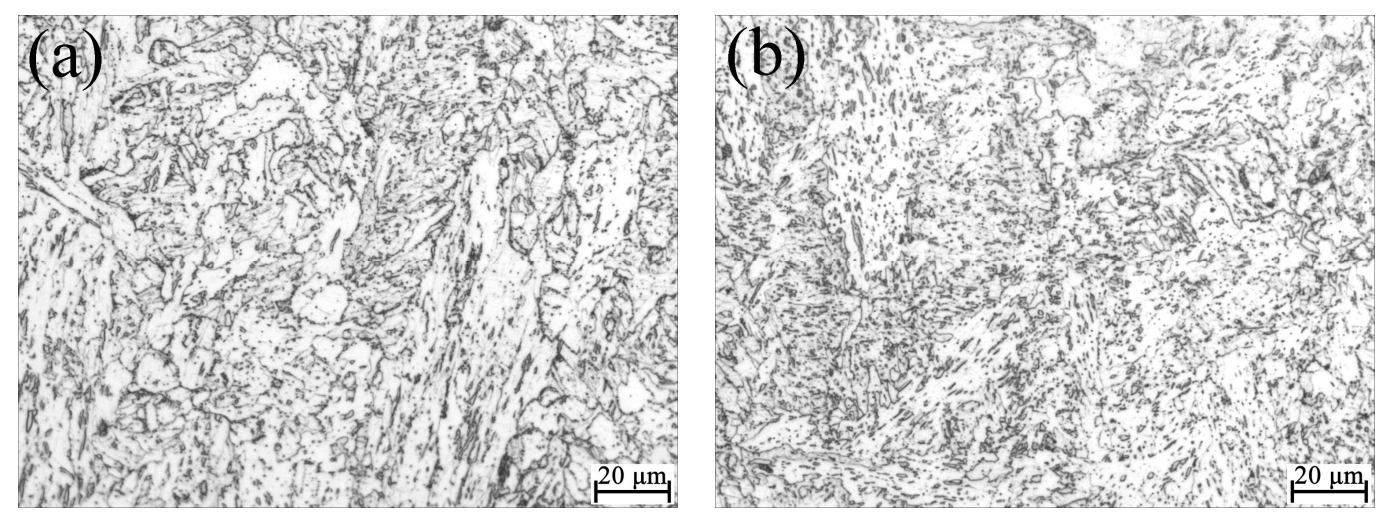

Figure 11. Microstructure of the FP2 of sample JT-C: (a) close to the heat source; (b) far from the heat source.

A fraction of the various FP2 microstructures in each cascade sample was analyzed to observe the microstructural changes in the different cascade welding samples of FP2 (Figure 12a). The center position of FP2 in each cascade sample was used to analyze the phase fraction because of the microstructural inhomogeneity of FP2. Therefore, the result only indicates the general trend of microstructural changes. In the phase analysis, six metallographic photographs were taken from FP2 of each cascade specimen. We circled a phase in each photograph and the software Image-Pro plus (6.0 version, Media Cybernetics, Houston, TX, USA) could automatically recognize the microstructure with the same characteristics and the areas of the phase in the photograph was used to calculate the content of the phase. In each cascade specimen, the average of six metallographic photographs was used in the research. Microstructures GB and BF were the main phases in the weld metal. Generally, GB is a hard and brittle phase with almost no high-angle grain boundaries existing. So, the presence of coarse GB is harmful to toughness, whereas that of BF is beneficial [29]. The content of GB did not change considerably during the entire welding process. The change in BF was larger than that of GB. In the FP2 of sample JT-C, large numbers of PF and QF appeared at the maximum heating temperature in the fourth thermal cycle $\left(\sim 700^{\circ} \mathrm{C}\right)$. Thus, BF, PF, and QF were beneficial to the weld metal toughness, whereas GB and M-A constituents were harmful to the toughness. Thus, the relationship between 
the content of GB and M-A constituents and weld metal toughness was investigated in this study, as shown in Figure 12b,c, respectively. The content variations of GB and M-A constituents in FP2 during the entire welding process were the same. The trend showed a decrease in the contents of GB and M-A constituents in FP2 after the single thermal cycle (sample JT-3) and then an increase after double thermal cycles (sample JT-4). After triple and quadruple thermal cycles, the contents of GB and M-A constituents in FP2 decreased again and tended to be stable.
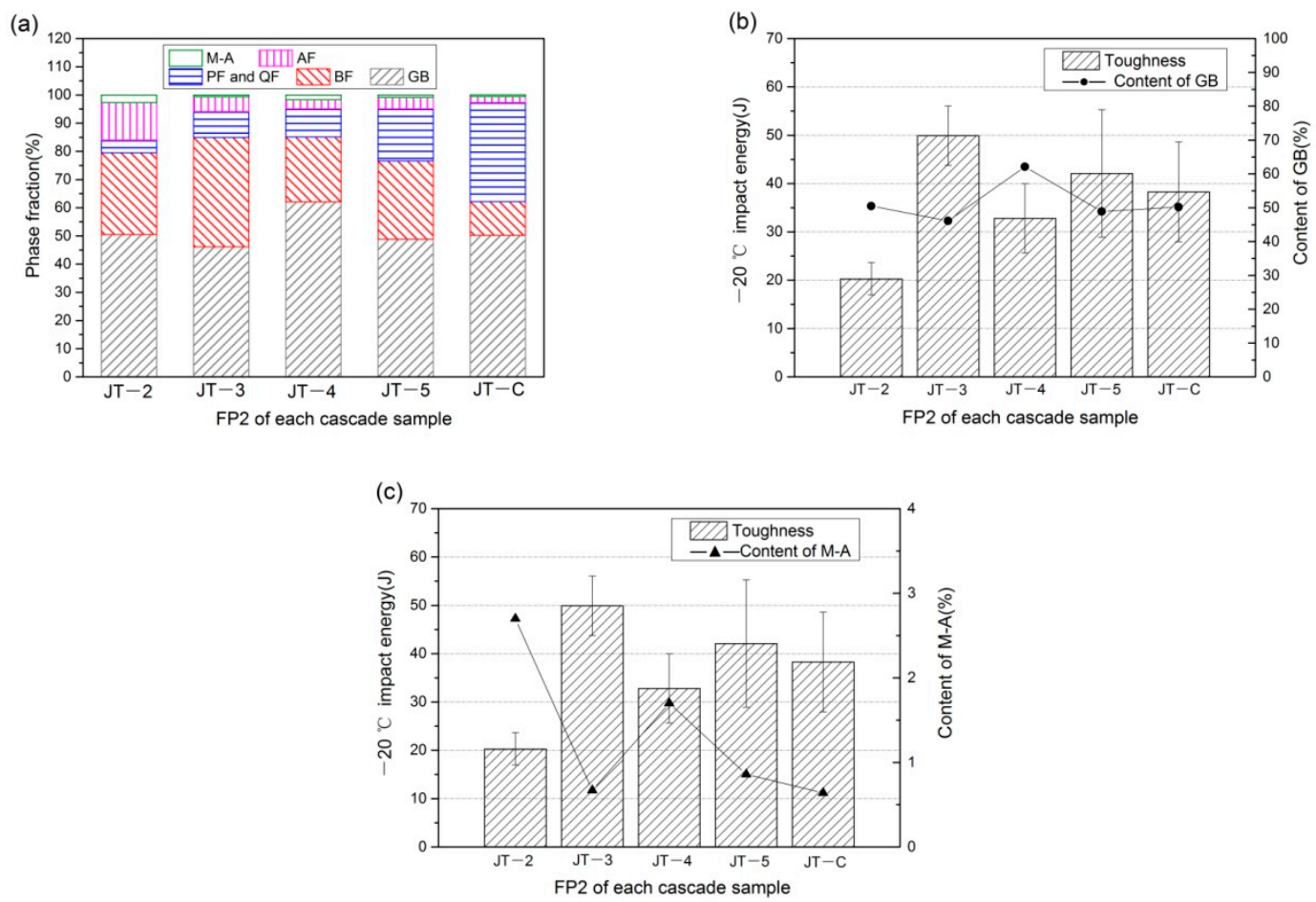

Figure 12. Various phases and toughness: (a) fraction of the various phases of FP2 in the cascade samples; (b) trend in GB content and the toughness in FP2 for different cascade samples; (c) trend in $\mathrm{M}-\mathrm{A}$ content and the toughness in FP2 for different cascade samples.

\subsection{Grain Size}

The average grain size in the FP2 of each cascade sample is shown in Figure 13a. Welding thermal cycles affected the grain size of the microstructure. The GBs were visualized by treating the surface of the metallographic samples. Given that the grain size of FP2 after each welding thermal cycle was different, the statistical result showed the average grain size of FP2. A coarse grain has a smaller crystal interface and the grain boundary is straight. In addition, cracks propagate and develop easily, which is harmful to the strength and toughness [30]. For sample JT-2, the average grain diameter of FP2 was $119 \mu \mathrm{m}$, which had the worst toughness. After the single thermal cycle of sample JT-3, the average grain diameter was reduced to $42 \mu \mathrm{m}$, which had the best toughness. The average grain diameter of the FP2 of sample JT-4 increased to $55 \mu \mathrm{m}$ while toughness decreased. After triple and quadruple thermal cycles in samples JT-5 and JT-C, the average grain diameter of FP2 decreased again and tended to be stable. The relationship between average grain size and toughness of FP2 is shown in Figure $13 \mathrm{~b}$. The FP2 of sample JT-2 had the worst toughness with the largest grain size, whereas that of sample JT-3 had the best toughness with the smallest grain size. For the sample JT-4 to JT-C, the difference in average grain size was not significant. There is more than one factor affecting weld metal toughness; the effect of GB content and M-A constituents may all be included. With the increase in the number of welding thermal cycles, the structure of the welding layer becomes more uniform, such as JT-4 to JT-C. Based on this, the grain size of the welding layer is no longer an important consideration, and the 
difference in toughness of FP2 between JT-4, JT-5, and JT-C was significantly smaller than that in JT-2 and JT-3.
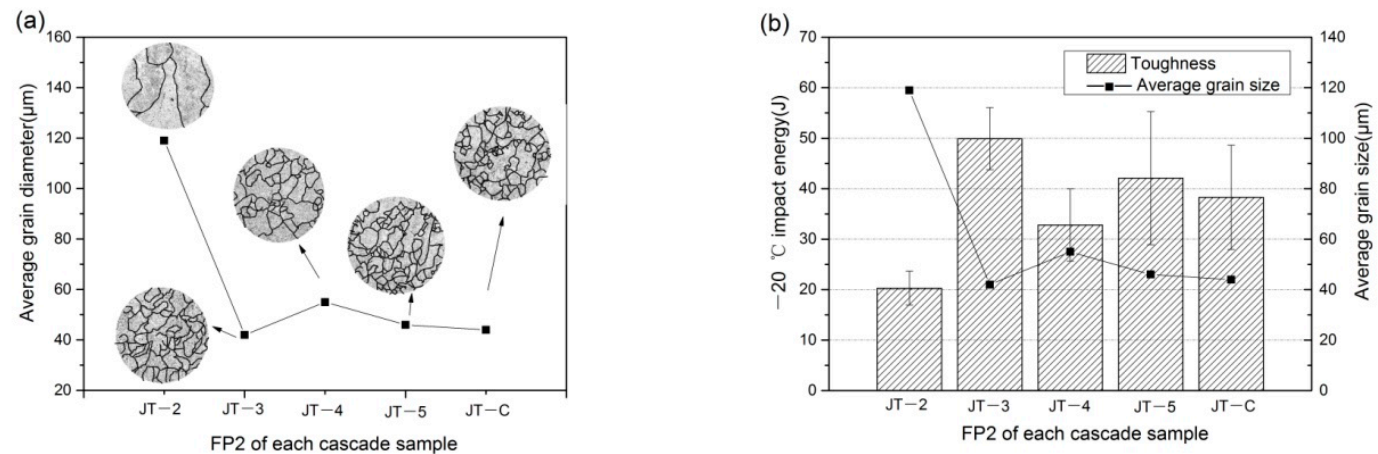

Figure 13. Average grain size and toughness: (a) average grain size of FP2 for different cascade samples; (b) trend in average grain size and the toughness of FP2 for different cascade samples.

\section{7. $M-A$ Constituents}

The M-A constituents in FP2 were etched using LePera reagent and analyzed using Image Pro Plus software. For morphology measurement, the M-A constituents were characterized by their morphological parameters, namely, maximal size $L_{\max }$ and minimal size $L_{\min }$ (which are designated, respectively, as the minimal and maximal "Feret diameter" in Image Pro Plus software. Aspect ratio $L_{\max } / L_{\min }$ characterized the elongation of a given M-A constituent. The larger the aspect ratio, the longer the M-A constituent, which implied that the M-A constituent had a slender morphology. In the FP2 of each cascade sample, $3000 \mathrm{M}-\mathrm{A}$ constituents were included in the morphology measurement to avoid incomplete statistics. The results are shown in Figure 14. The data distribution indicated a clear trend in M-A constituents during the welding thermal cycle. In FP2 in JT-2, the number of M-A constituents, of which their maximal size $L_{\max }$ was larger than $5 \mu \mathrm{m}$, was more than other cascade specimens (Figure 14a). Thus, the M-A constituents in the FP2 of sample JT-2 were large and massive. After the M-A constituents experienced the heating effect of FP3, their size in FP2 was drastically reduced (Figure 14b). The maximum value of $L_{\max }$ in the M-A constituents in FP2 of sample JT-3 was almost below $7.5 \mu \mathrm{m}$, while that in FP2 of sample JT-2 reached $12.5 \mu \mathrm{m}$. When FP4 was finished, the aspect ratio $\left(L_{\max } / L_{\min }\right)$ increased, which meant the slender morphology of the M-A constituents in FP2 became more evident (Figure 14c). The M-A constituents decomposed at $\sim 700{ }^{\circ} \mathrm{C}$ because the maximum heating temperature of the third and fourth thermal cycles was at that temperature [31]. Thus, the maximal size $L_{\max }$ of the M-A constituents in FP2 of samples JT- 5 and JT-C were smaller than that of sample JT-4 (Figure 14d,e). In particular, the FP2 of sample JT-C had the smallest size of M-A constituents and had the most apparent slender morphology of all M-A constituents. With respect to weld metal toughness, smaller-sized (FP2 of samples JT-3 and JT-5) and slenderer M-A constituents (FP2 of sample JT-C) had little effect on toughness. Massive M-A constituents could reduce weld metal toughness (FP2 of sample JT-2), and the special distribution of M-A constituents (necklace-type) at the inter-critical temperature between $\mathrm{A}_{\mathrm{c} 1}$ and $\mathrm{A}_{\mathrm{c} 3}$ could affect weld toughness considerably (FP2 of sample JT-4). 

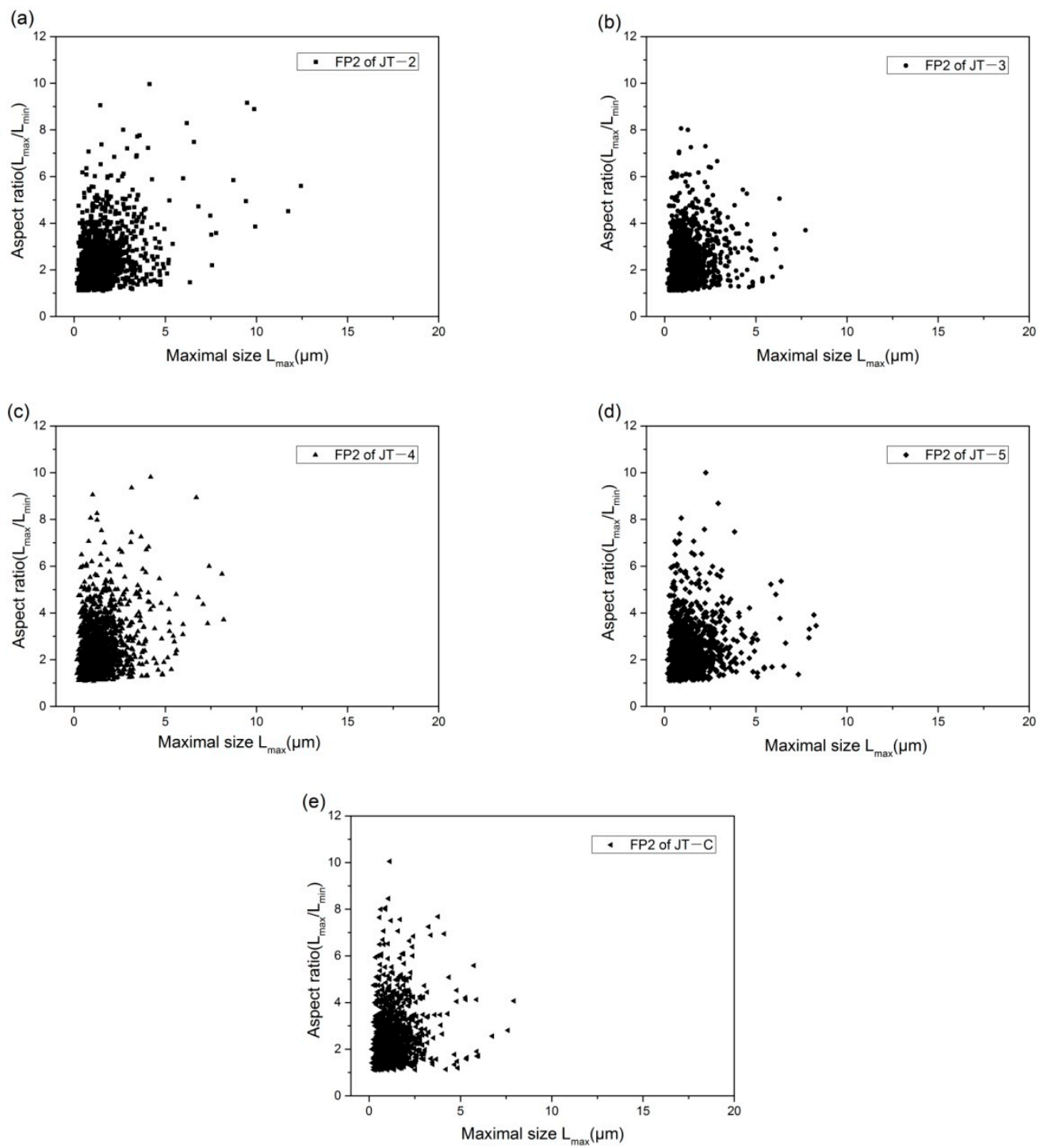

Figure 14. Statistics on morphology of about $3000 \mathrm{M}-\mathrm{A}$ constituents in FP2 for different cascade samples: FP2 of samples (a) JT-2; (b) JT-3; (c) JT-4; (d) JT-5; and (e) JT-C.

In Figure 15, the TEM image of FP2 of sample JT-4 showed the presence of stress concentration around the M-A constituents, causing crack initiation under stress, which could reduce the toughness (marked with a yellow circle). Figure 16 shows the SEM images taken from the fracture surface from one of the impact samples JT- 2 and JT- 5 at $-20{ }^{\circ} \mathrm{C}$. The impact energy of sample JT- 5 was unstable and, thus, the sample with lower impact energy was selected for analysis. Both samples produced low impact value. The position of the cleavage initiators of sample JT-2 is shown in Figure 16a. The initiators were classified as M-A constituents, as shown in Figure 16b (yellow arrows). The M-A constituents were also found in the fracture surface in the FP2 of sample JT-5 (Figure 16c,d). The possibility of cleavage increased because of the presence of M-A constituents [32]. Following the river pattern throughout each cleavage plane all over the fracture surface helped define the position of these $\mathrm{M}-\mathrm{A}$ constituents. Because of the better toughness, the fracture surface of FP2 in JT-3 showed as small dimples (Figure 16e). 


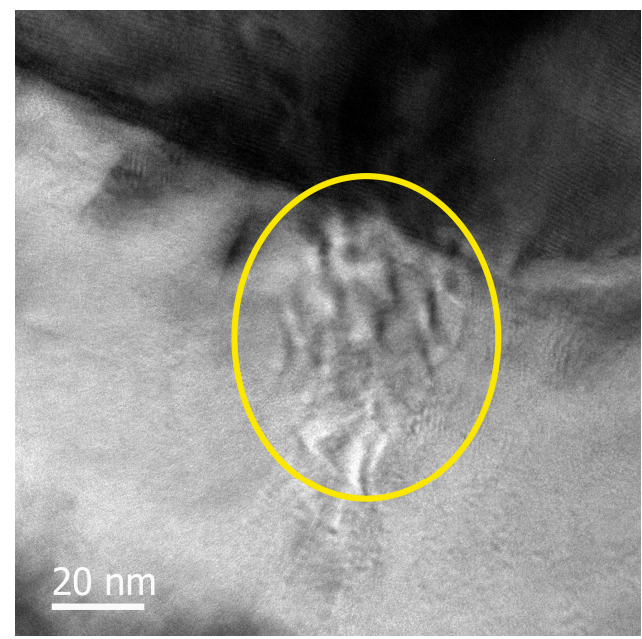

Figure 15. TEM of stress concentration around the M-A constituents in FP2.
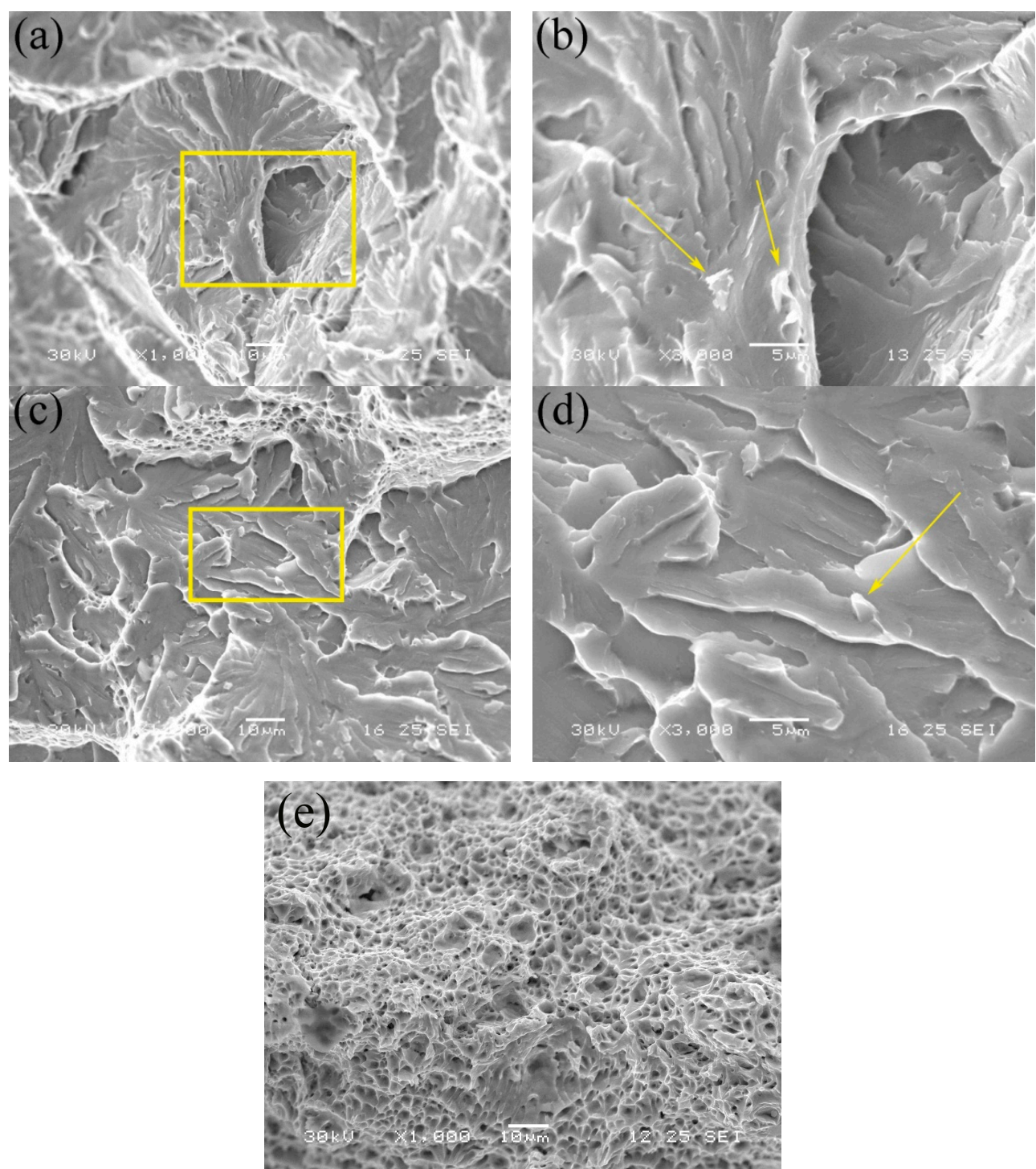

Figure 16. SEM images of the fracture surface in FP2: (a) fracture surface in the FP2 of sample JT-2 with an impact energy of $16 \mathrm{~J}$; (b) enlarged view of the yellow box area in (a); (c) fracture surface in the FP2 of sample JT-5 with an impact energy of $25.5 \mathrm{~J}$; (d) enlarged view of the yellow box area in (c); (e) fracture surface in the FP2 of sample JT-3. 


\subsection{Analysis}

The preceding analysis indicates that some factors considerably influence the weld metal toughness, namely, M-A constituents, average grain size of the microstructure, and GB content. The change rule of GB content and toughness was not obvious. The relationships between the two factors (content of $\mathrm{M}-\mathrm{A}$ constituents and average grain size of the microstructure) and the weld toughness are shown in Figure 17a,b. The data were fitted by curves with minimum errors. The findings showed that the content of M-A constituents and the grain size were all inversely proportional to weld metal toughness.
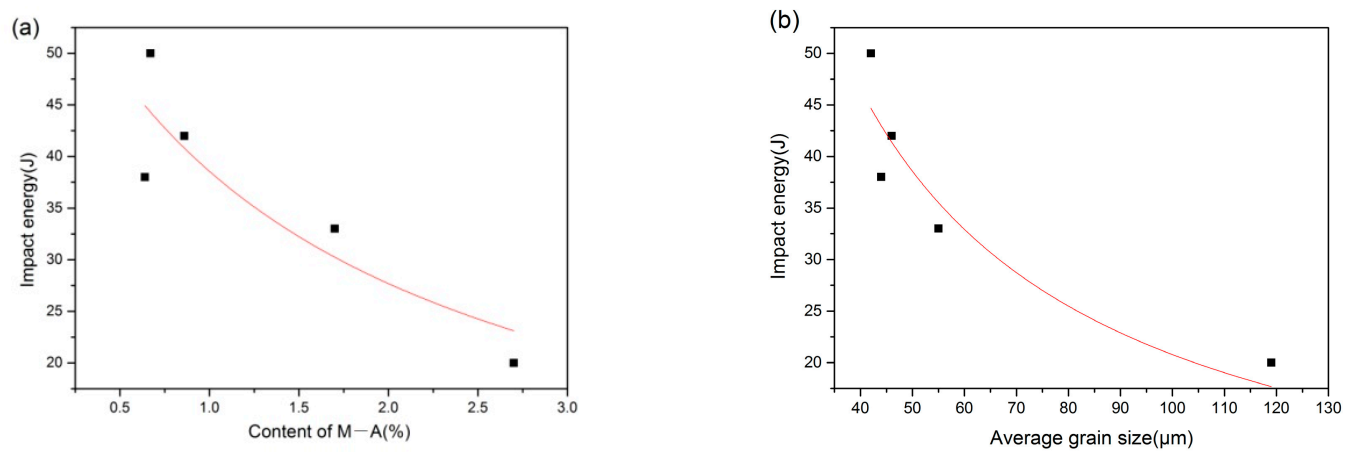

Figure 17. Two factors and toughness of FP2: (a) impact energy and content of M-A; (b) impact energy and average grain size.

The relationship between the content of M-A constituents and weld metal toughness can be expressed by Equation (1), and the average grain size and weld metal toughness can be expressed by Equation (2). These equations can determine the microstructural characteristic of the weld metal in one FP through the impact energy.

$$
\begin{gathered}
\mathrm{IE}=1 /\left(0.0157+0.0101 \mathrm{C}_{\mathrm{M}-\mathrm{A}}\right) \\
\mathrm{IE}=1 /(0.00375+0.000443 \mathrm{~d})
\end{gathered}
$$

where IE denotes impact energy, $\mathrm{J} ; \mathrm{C}_{\mathrm{M}-\mathrm{A}}$ refers to the content of $\mathrm{M}-\mathrm{A}$ constituents, \%; and $\mathrm{d}$ is the average grain size, $\mu \mathrm{m}$.

The research in this paper showed that, in addition to the two factors above, both large and necklace-type M-A constituents were detrimental to weld metal toughness. Therefore, all the factors should be controlled to effectively improve the impact toughness of multi-pass weld metal. To achieve this goal, the chemical composition of the welding wire or the welding parameters between different welding passes could be changed.

In addition, if the welded joint is used for the girth weld connection of the pipe, then it can be divided into three zones [33]: $20 \%$ of thickness from the inner surface, $20 \%$ of thickness from the outer surface, and the middle $60 \%$ of section thickness (Figure 18). The highest data on residual stress were found at mid-thickness. The maximum and average residual stress near the outer surface tended to be greater than those near the inner surface. Thus, cap weld, which did not undergo any welding thermal cycle, and FP4, which underwent double welding thermal cycles, had the lowest mechanical properties (deformation ability and toughness) for the entire welded joint. The cap weld was in the outer zone, and FP4 was in the middle zone. These two weld layers had the worst toughness and would be more affected by residual stress compared with other weld layers. Furthermore, tensile residual stress could cause cracks. Crack initiation and propagation in these two weld layers could, therefore, easily occur compared with other weld layers. 


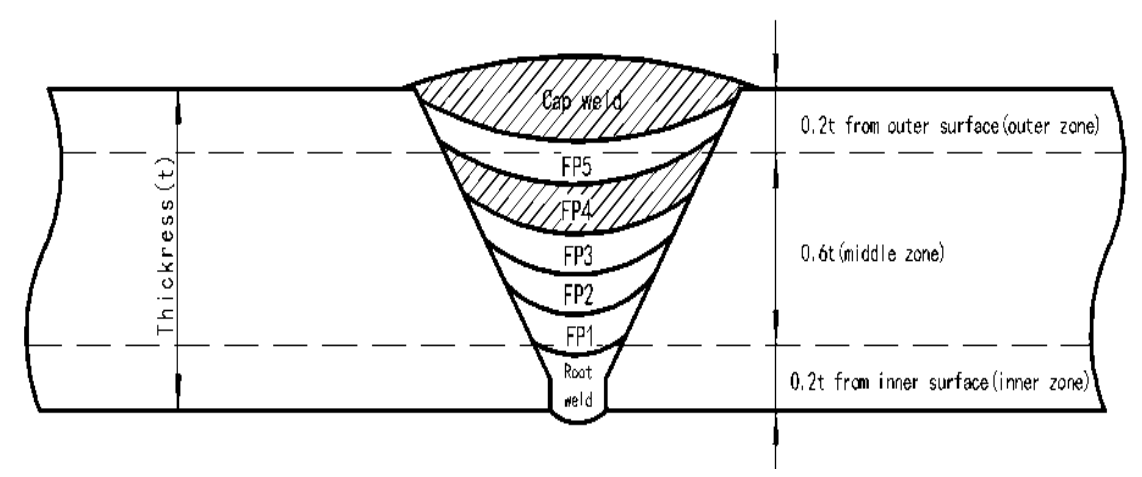

Figure 18. Schematic of three distances separated from the pipe wall thickness.

\section{Conclusions}

Cascade welding can reveal the changes in the microstructure and toughness of actual weld layers during the welding process. In this study, FP2 underwent quadruple thermal cycles. Each time a thermal cycle was performed, the microstructure and toughness of FP2 changed.

(1) Yield and tensile strength showed an approximate linear relationship with the Vickers hardness in the FP2 in each cascade specimen, and the original FP2 and FP2 after double thermal cycles (JT-2 and JT-4) had the worse deformation ability.

(2) The toughness of FP2 after a single thermal cycle improved, decreased after double thermal cycles, and improved again after triple thermal cycles. Weld metal toughness did not improve further after quadruple thermal cycles. Therefore, on the basis of the total number of weld layers, the number of thermal cycles each weld layer experienced and the toughness of each weld layer could be obtained.

(3) The FP2 microstructure was not uniform after a single thermal cycle. The WM-CG, WM-CFG, and WM-FG regions were formed when FP2 underwent the single thermal cycle. However, microstructural uniformity increased along with the increase in the number of thermal cycles.

(4) The content of each phase in the microstructure of FP2 changed under different thermal cycles. Granular bainite (GB) and Bainitic ferrite (BF) were the main phases in FP2 during the entire welding process. However, the content of the M-A constituents and the toughness of FP2 revealed a certain relationship, that is, the content of the M-A constituents was inversely proportional to FP2 toughness. Average grain size and toughness of FP2 also had the same relationship.

(5) In the samples with low impact toughness, stress concentration was observed around the M-A constituents in the FP2 microstructure. Large massive M-A constituents and necklace-type M-A constituents were harmful to the toughness. The total content of M-A constituents was inversely proportional to the weld metal toughness.

(6) The weld layer that did not undergo any welding thermal cycle and the weld layer that underwent two welding thermal cycles had the worst toughness. These weld layers were more affected by residual stress compared with other weld layers.

Author Contributions: Writing—original draft, Formal analysis, F.B.; Supervision, Writing—review and editing, H.D.; Project administration, Writing—review and editing, L.T.; Supervision, Writing—review and editing, L.P.; Project administration, Writing - review and editing, L.W.

Funding: This study was partially supported by the National Natural Science Foundation of China (No. 51206010).

Acknowledgments: The work was supported by the China Petroleum Natural Gas Pipeline Science Research Institute.

Conflicts of Interest: The authors declare no conflict of interest. 


\section{References}

1. Alipooramirabad, H.; Paradowska, A.; Ghomashchi, R.; Reid, M. Investigating the effects of welding process on residual stresses, microstructure and mechanical properties in HSLA steel welds. J. Manuf. Process. 2017, 28, 70-81. [CrossRef]

2. Cristina, C.; Mariane, C.; Manuel, P.L.; Antonio, D.A.; Francisco, A.F.; Jose, M.S.A. Laser Hybrid Butt Welding of Large Thickness Naval Steel. Metals 2019, 9, 100. [CrossRef]

3. Sung, H.K.; Sin, S.Y.; Cha, W.; Oh, K.; Lee, S.; Kim, N.J. Effects of acicular ferrite on charpy impact properties in heat affected zones of oxide-containing API X80 linepipe steels. Mater. Sci. Eng. A 2011, 528, 3350-3357. [CrossRef]

4. Eva, Z.; Ján, S. Mechanical and microstructural investigations of the laser welding of different zinc-coated steels. Metals 2019, 9, 1-13.

5. Zhang, X.G.; Li, L.Q.; Chen, Y.B.; Zhu, X.C.; Ji, S.J. Numerical simulation analysis of dual-beam laser welding of tailored blanks with different thicknesses. Metals 2019, 9, 135. [CrossRef]

6. Wang, H.; Woo, W.; Kim, D.K.; Em, V. Effect of chemicaldilution and the number of weld layers on residual stresses in a multi-pass low-transformation temperature weld. Mater. Des. 2018, 160, 384-394. [CrossRef]

7. Luo, X.; Chen, X.H.; Wang, T.; Pan, S.W.; Wang, Z.D. Effect of morphologies of martensite-austenite constituents on impact toughness in intercritically reheated coarse-grained heat-affected zone of HSLA steel. Mater. Sci. Eng. A 2018, 710, 192-199. [CrossRef]

8. Lan, L.Y.; Qiu, C.L.; Zhao, D.W.; Gao, X.H.; Du, L.X. Analysis of martensite-austenite constituent and its effect on toughness in submerged arc welded joint of low carbon bainitic steel. J. Mater. Sci. 2012, 47, 4732-4742. [CrossRef]

9. Li, X.D.; Fan, Y.R.; Ma, X.P.; Subramanian, S.V.; Shang, C.J. Influence of martensite-austensite constituents formed at different intercritical temperatures on toughness. Mater. Des. 2015, 67, 457-463. [CrossRef]

10. Mohammadijoo, M.; Valloton, J.; Collins, L.; Henein, H.; Ivey, D.G. Characterization of martensite-austenite constituents and micro-hardness in intercritical reheated and coarse-grained heat affected zones of API X70 HSLA steel. Mater. Charact. 2018, 142, 321-331. [CrossRef]

11. Lan, H.F.; Du, L.X.; Misra, R.D.K. Effect of microstructural constituents on strength-toughness combination in a low carbon bainitic steel. Mater. Sci. Eng. A 2014, 611, 194-200. [CrossRef]

12. Zheng, C.C.; Wang, X.M.; Li, S.R. Effects of inclusions on microstructure and properties ofheat-affected-zone for low-carbon steels. Sci. China Technol. Sci. 2012, 55, 1556-1565. [CrossRef]

13. Moeinifar, S.; Kokabi, A.H.; Hosseini, H.R.M. Influence of peak temperature during simulation and real thermal cycles on microstructure and fracture properties of the reheated zones. Mater. Des. 2010,31, $2948-2955$. [CrossRef]

14. Haugen, V.G.; Rogne, B.R.S.; Akselsen, O.M.; Thaulow, C.; Østby, E. Local mechanical properties of intercritically reheated coarse grained heat affected zone in low alloy steel. Mater. Des. 2014, 59, $135-140$. [CrossRef]

15. Zhang, W.D.; Zhao, G.Q.; Fu, Q.J. Study on the effects and mechanisms of induction heat treatment cycles on toughness of high frequency welded pipe welds. Mater. Sci. Eng. A 2018, 736, 276-287. [CrossRef]

16. Maresca, F.; Kouznetsova, V.G.; Geers, M.G.D.; Curtin, W.A. Contribution of austenite-martensite transformation to deformability of advanced high strength steels: From atomistic mechanisms to microstructural response. Acta. Mater. 2018, 156, 463-478. [CrossRef]

17. Huda, N.; Midawi, A.R.H.; Gianetto, J.; Lazor, R.; Gerlich, A.P. Influence of martensite-austenite(MA) on impact toughness of X80 line pipe steels. Mater. Sci. Eng. A 2016, 662, 481-491. [CrossRef]

18. Ci, Y.; Zhang, Z.Z. Simulation study on heat-affected zone of high-strain X80 pipeline steel. J. Iron Steel Res. Int. 2017, 24, 966-972. [CrossRef]

19. Lee, S.G.; Sohn, S.S.; Kim, B.; Kim, W.G.; Um, K.K.; Lee, S. Effects of martensite-austenite constituent on crack initiation and propagation in inter-critical heat-affected zone of high-strength low-alloy (HSLA) steel. Mater. Sci. Eng. A 2018, 715, 332-339. [CrossRef]

20. Kumar, S.; Nath, S.K. Effect of weld thermal cycles on microstructures and mechanical properties in simulated heat affected zone of a HY 85 steel. Trans. Indian Inst. Met. 2017, 70, 239-250. [CrossRef] 
21. Wang, X.L.; Nan, Y.R.; Xie, Z.J.; Tsai, Y.T.; Yang, J.R.; Shang, C.J. Influence of welding pass on microstructure and toughness in the reheated zone of multi-pass weld metal of 550MPa offshore engineering steel. Mater. Sci. Eng. A 2017, 702, 196-205. [CrossRef]

22. Xie, Z.J.; Han, G.; Zhou, W.H.; Wang, X.L.; Shang, C.J.; Misra, R.D.K. A novel multi-step intercritical heat treatment induces multi-phase microstructure with ultra-low yield ratio and high ductility in advanced high-strength steel. Scr. Mater. 2018, 155, 164-168. [CrossRef]

23. Martinez Krahmer, D.; Polvorosa, R.; Lopez de Lacalle, L.N.; Alonso-Pinillos, U.; Abate, G.; Riu, F.A. Alternatives for specimens manufacturing in tensile testing of steel plates. Exp. Tech. 2016, 40, 1555-1565. [CrossRef]

24. Zhang, S.H.; Zhao, D.W.; Wang, X.N. Influence of yield-to-tensile strength ratio(Y/T) on failure assessment of defect-free and corroded X70 steel pipeline. J. Cent. South Univ. 2014, 21, 460-465. [CrossRef]

25. Pavlina, E.J.; Van Tyne, C.J. Correlation of Yield Strength and Tensile Strength with Hardness for Steels. J. Mater. Eng. Perform. 2008, 17, 888-893. [CrossRef]

26. Li, Y.; Baker, T.N. Effect of morphology of martensite-austenite phase on fracture of weld heat affected zone in vanadium and niobium microalloyed steels. Mater. Sci. Technol. 2010, 26, 1029-1040. [CrossRef]

27. Mohseni, P.; Solberg, J.K.; Karlsen, M.; Akselsen, O.M.; Østby, E. Cleavage fracture initiation at M-A constituents in intercritically coarse-grained heat-affected zone of a HSLA steel. Metall. Mater. Trans. 2014, 45, 384-394. [CrossRef]

28. Wang, X.L.; Wang, Z.Q.; Dong, L.L.; Shang, C.J.; Ma, X.P.; Subramanian, S.V. New insights into the mechanism of cooling rate on the impact toughness of coarse grained heat affected zone from the aspect of variant selection. Mater. Sci. Eng. A 2017, 704, 448-458. [CrossRef]

29. Shim, D.H.; Lee, T.; Lee, J.; Lee, H.J.; Yoo, J.Y.; Lee, C.S. Increased resistance to hydrogen embrittlement in high-strength steels composed of granular bainite. Mater. Sci. Eng. A 2017, 700, 473-480. [CrossRef]

30. Cao, R.; Li, J.; Liu, D.S.; Ma, J.Y.; Chen, J.H. Micromechanism of decrease of impact toughness in coarse-grain heat-affected zone of HSLA steel with increasing welding heat input. Metall. Mater. Trans. A 2015, 46, 2999-3014. [CrossRef]

31. Wang, X.L.; Wang, X.M.; Shang, C.J.; Misra, R.D.K. Characterization of the multi-pass weld metal and the impact of retained austenite obtained through intercritical heat treatment on low temperature toughness. Mater. Sci. Eng. A 2016, 649, 282-292. [CrossRef]

32. Fang, Z.; Li, A.Q.; Bao, H.Y. Calculation of stress intensity factor in two-dimensional cracks by strain energy density factor procedure. Sci. China Technol. Sci. 2018, 61, 542-550. [CrossRef]

33. Mirzaee-Sisan, A.; Wub, G. Residual stress in pipeline girth welds-A review of recent data and modeling. Int. J. Press. Vessel. Pip. 2019, 169, 142-152. [CrossRef] 